\title{
Suspected new wave of muscular sarcocystosis in travellers returning from Tioman Island, Malaysia, May 2014
}

D Tappe (tappe@bnitm.de) ${ }^{1}$, A Stich ${ }^{2}$, A Langeheinecke ${ }^{3}$, F von Sonnenburg ${ }^{4}$, B Muntau ${ }^{1}$, J Schäfer ${ }^{5}$, G Slesak ${ }^{5}$

1. Bernhard Nocht Institute for Tropical Medicine, Hamburg, Germany

2. Medical Mission Hospital, Department for Tropical Medicine, Würzburg, Germany

3. Medizinische Klinik 1, Klinikum Saarbrücken, Saarbrücken, Germany

4. Department of Infectious Diseases and Tropical Medicine, Section of International Medicine and Public Health, University of Munich, Munich, Germany

5. Tropenklinik Paul-Lechler-Hospital, Department of Tropical Medicine, Tübingen, Germany

Tappe D, Stich A, Langeheinecke A, von Sonnenburg F, Muntau B, Schäfer J, Slesak G. Suspected new wave of muscular sarcocystosis in travellers returning from Tioman Island, Malaysia, May 2014. Euro Surveill. 2014;19(21):pii=20816. Available online: http://www.eurosurveillance.org/ViewArticle.aspx?Articleld=20816

In May 2014, six patients presented in Germany with a Sarcocystis-associated febrile myositis syndrome after returning from Tioman Island, Malaysia. During two earlier waves of infections, in 2011 and 2012, about 100 travellers returning to various European countries from the island were affected. While the first two waves were associated with travel to Tioman Island mostly during the summer months, this current series of infections is associated with travel in early spring, possibly indicating an upcoming new epidemic.

Here we report the clinical and laboratory findings of a new, third wave of Sarcocystis-associated febrile myositis syndrome in travellers returning to Germany from Tioman Island, Malaysia, in spring 2014.

\section{Case series}

Six previously healthy German patients, aged 15-44 years were seen in early May 2014 in travel clinics in Tübingen, Saarbrücken and Munich, with a febrile myositis syndrome after travel. The patients (three female, three male) complained of current or very recent episodes of fever of up to $40^{\circ} \mathrm{C}$, headache and myalgia. All had returned at the end of March to the end of April from Tioman Island, Malaysia. Laboratory investigations revealed eosinophilia in all but one and elevated muscle enzyme levels in half of the patients (Table). There were no clinically relevant electrocardiogram abnormalities but mild splenomegaly was seen in some. Serological tests for trichinellosis, toxoplasmosis and dengue virus infection were negative in all patients. Tests for chikungunya virus antibodies were not carried out for one patient, but negative in all others. All patients had stayed in the north-west of Tioman Island and developed symptoms 1-18 days (mean: 10) after leaving the island. Their travel history, including locality of lodging on the island, estimated incubation time (a few days to three weeks), clinical picture and laboratory results were consistent with the Sarcocystisassociated febrile myositis syndrome seen in travellers returning to various European countries from Tioman Island in 2011 and 2012 [1-4]. No such series of infections were seen in 2013.

\section{Patients 1-3}

In three patients who sought medical attention 1-6 days after first onset of fever, headache and slight myalgia (i.e. in the early, rather non-specific phase of clinical disease) and who had no elevated creatine kinase (CK) levels, therapy with trimethoprim/sulfamethoxazole (cotrimoxazole) $(2 \times 960 \mathrm{mg} /$ day $)$ [4] was started within a few days. All three improved clinically but developed higher eosinophilia after 7-20 days, yet there was no elevation of CK level.

\section{Patients 4-5}

A couple presented in a later phase of the disease. One patient was currently asymptomatic with moderate CK elevation 23 days after a previous short-lived febrile episode. The other had fever and severe myalgia plus high eosinophilia and CK elevation 28 days after onset of a short-lived episode with high fever, headaches and night sweats. Both showed a further increase of eosinophil counts (maximum count of $500 / \mu \mathrm{l}$ and $5,260 /$ $\mu \mathrm{l}$, respectively) after the start of cotrimoxazole treatment. The previously symptom-free patient developed moderate myalgia together with increasing CK levels thereafter; the other had to be started on high-dose steroids four days later (prednisolone starting dose $100 \mathrm{mg} /$ day) because of intensifying severe myalgia.

\section{Patient 6}

The patient with the longest interval ( 43 days) since onset of first symptoms (fever, headache, myalgia) was treated with steroids (prednisolone starting dose $40 \mathrm{mg} /$ day).

Administration of steroids resulted in rapid clinical improvement in both patients (Patients 5 and 6), similar to observations during the first two waves of 
Characteristics of patients returning from Tioman Island, Malaysia, with Sarcocystis-associated febrile myositis syndrome, May $2014(n=6)$

\begin{tabular}{|c|c|c|c|c|c|c|c|}
\hline \multirow{2}{*}{ Characteristic } & \multicolumn{6}{|c|}{ Patient number } & \multirow{2}{*}{ Norm } \\
\hline & 1 & 2 & 3 & 4 & 5 & 6 & \\
\hline Sex & $M$ & $\mathrm{~F}$ & M & $\mathrm{F}$ & $M$ & $\mathrm{~F}$ & - \\
\hline $\begin{array}{l}\text { Days from departure from } \\
\text { Tioman Island, Malaysia, until } \\
\text { symptom onset }\end{array}$ & 9 & 12 & 7 & 18 & 13 & 1 & - \\
\hline Myalgia (yes/no) & yes & yes & yes & yes & yes & yes & - \\
\hline $\begin{array}{l}\text { Maximum pain (score } 0=\text { none } \\
\text { to } 10=\text { maximum) }\end{array}$ & 2 & 4 & 4 & 6 & 9.5 & 8 & - \\
\hline Arthralgia (yes/no) & yes & yes & yes & no & no & yes & - \\
\hline Headache (yes/no) & yes & yes & yes & yes & yes & yes & - \\
\hline Neck pain (yes/no) & no & yes & yes & no & yes & yes & - \\
\hline Body temperature $\left({ }^{\circ} \mathrm{C}\right)$ & No data & 38 & 38 & 38 & 40 & 40 & - \\
\hline \multicolumn{8}{|l|}{ Laboratory tests } \\
\hline Creatine kinase (U/L) & 138 & 80 & 133 & 159 & 207 & 450 & $\begin{array}{l}\text { «170 males; } \\
\ll 145 \text { females }\end{array}$ \\
\hline $\begin{array}{l}\text { Creatine kinase MB fraction } \\
(\mathrm{U} / \mathrm{L})\end{array}$ & 21 & 15 & 14 & 22 & 35 & 9 & $\begin{array}{l}<25 \text { or }<6 \% \text { of } \\
\text { total creatine } \\
\text { kinase } \\
\end{array}$ \\
\hline $\begin{array}{l}\text { Cardiac troponin (troponin I/ } \\
\text { troponin } \mathrm{T}, \mu \mathrm{g} / \mathrm{L} \text { ) }\end{array}$ & $<0.014$ & $<0.014$ & $<0.014$ & Negative & Negative & Not done & $<0.4$ \\
\hline Lactate dehydrogenase (U/L) & 326 & 342 & 383 & 201 & 324 & 307 & $<240$ \\
\hline $\begin{array}{l}\text { Aspartate amino transferase } \\
(\mathrm{U} / \mathrm{L})\end{array}$ & 49 & 56 & 46 & 18 & 39 & 23 & $\begin{array}{l}\text { «50 males; } \\
\ll 35 \text { females } \\
\end{array}$ \\
\hline Eosinophil count per $\mu \mathrm{l}$ & 430 & 620 & 260 & 170 & 4,490 & 1,150 & $\ll 350$ \\
\hline Eosinophils (\%) & 9 & 8 & 4 & 8 & 41 & 12 & 〈7 \\
\hline Spleen length $(\mathrm{cm})$ & 13.2 & 9.2 & 13.0 & No data & 12.1 & 12.5 & $<11$ \\
\hline Treatment & $\begin{array}{l}\text { Co- } \\
\text { trimoxazole }\end{array}$ & $\begin{array}{l}\text { Co- } \\
\text { trimoxazole }\end{array}$ & $\begin{array}{l}\text { Co- } \\
\text { trimoxazole }\end{array}$ & $\begin{array}{l}\text { Co- } \\
\text { trimoxazole }\end{array}$ & $\begin{array}{l}\text { Cotrimoxazole } \\
\text { plus } \\
\text { prednisolone } \\
\end{array}$ & Prednisolone & - \\
\hline $\begin{array}{l}\text { Days from symptom onset to } \\
\text { start of treatment }\end{array}$ & 6 & 3 & 8 & 23 & 28 & 43 & - \\
\hline
\end{tabular}

F: female; M: male.

a Trimethoprim/sulfamethoxazole.

Sarcocystis-associated febrile myositis syndrome in travellers returning from Tioman Island in 2011 and $2012[3,4]$.

In the current cluster, no muscle biopsies were taken and the presumptive diagnosis was based on the travel history, symptoms and blood test results of increasing eosinophil count and CK level and the exclusion of other infectious causes.

\section{Background}

Sarcocystosis is a cosmopolitan zoonotic disease that is caused by intracellular apicomplexan/coccidian parasites of the genus Sarcocystis, with more than 120 recognised species [5]. These protozoal parasites are maintained in a two-host life cycle involving a carnivore predator final host and its 'prey' as intermediate host, such as snake-rodent or human-cattle relationships, for example. In the intermediate host, invasive muscular sarcocystosis develops after infective Sarcocystis oocysts shed in faeces of an infected final host are ingested. Sporozoites are released from the oocysts, which invade muscular tissue of the intermediate host after several cycles of replication. In the myocytes, tube- or sac-like sarcocysts are eventually formed, which contain numerous single-celled bradyzoites. When the intermediate host falls prey to a carnivore or omnivore, the bradyzoites can complete their life cycle sexually in the intestine of the final host. Humans are final hosts for two Sarcocystis species, S. hominis and S. suihominis, which cause non-invasive self-limiting diarrhoeal symptoms [5]. However, humans can serve as accidental intermediate hosts after incidental ingestion of food faecally contaminated with oocysts for a presumed number of several Sarcocystis species, among them S. nesbitti, [6,7] and develop the invasive muscular form. Invasive muscular sarcocystosis causes fever and myalgia, but not diarrhoea, in contrast to the intestinal form. 
Already in 1991, sarcocystosis was regarded as a possible emerging food-borne zoonosis in Malaysia, as high human seroprevalence [8] and high positive autopsy rates [9] were found. In 1993, the first cluster of patients with symptomatic muscular sarcocystosis was seen in United States service personnel in rural Malaysia [10]. In 2011 and 2012, in a two-wave outbreak, the largest series of symptomatic muscular sarcocystosis in humans worldwide was noted in travellers returning to Europe from Tioman Island, Malaysia [1-4]. The course of disease was typically biphasic, with a prodromal stage of one week characterised by fever, myalgia and headache, followed by a two-week asymptomatic period and later by a long-lasting feverish episode with severe myalgia with eosinophilia and CK level elevation [4]. An environmental survey for Sarcocystis oocysts conducted in November 2011 on Tioman Island could not detect the source of infection [11].

Definitive diagnosis is achieved after muscle biopsy with histological demonstration of typical sarcocysts or by molecular methods $[3,6]$. However, despite severe myalgia, parasite density in the muscle is apparently low and sarcocysts have thus been detected in a few patients only $[3,4,6,10]$. |

\section{Conclusions}

This cluster of travellers with a febrile myositis syndrome returning from Tioman Island indicates the beginning of a third wave of a presumably Sarcocystisassociated invasive illness. In the first two waves, in 2011 and 2012, patients acquired the disease mainly in the summer months (July to October) [1-4]. In contrast, symptom onset in patients of this current new cluster took place in spring, possibly indicating a larger upcoming epidemic in returning travellers in the summer months of this year.

The source of the infection on the island has not been determined so far, but is obviously persisting or reemerging. The nearly simultaneous outbreak of invasive sarcocystosis among Malaysian students and teachers on a different Malaysian island, Pangkor [6], is intriguing. The snake-associated $S$. nesbitti $[6,7,12]$ was molecularly determined to be the causative agent on Pangkor. The quest for the Sarcocystis species involved, the source of infection and the animal reservoir on Tioman Island is currently ongoing. It remains to be determined whether environmental factors, such as climate change or increasing reptile populations (i.e. possible final hosts) [13], play a role in this disease (re-) emergence.

Physicians should be aware of this unusual re-emerging outbreak and pre-travel advice should be given regarding individual prevention measures, such as the consumption of cooked food, well-peeled fruit and pre-packed or boiled/filtered water only. Treatment with cotrimoxazole may be a therapeutic approach in the early phase of disease to prevent muscle invasion, whereas steroids seem effective to treat severe myalgia/myositis in the later phase.

Conflict of interest

None declared.

Authors' contributions

Wrote the manuscript: DT, AS, AL, FvS, JS, GS; performed laboratory or epidemiological investigations: DT, BM; performed data analysis: DT, AS, AL, FvS, JS, GS; performed patient examinations: JS, GS, AL, FvS.

\section{References}

1. Centers for Disease Control and Prevention (CDC). Notes from the field: acute muscular sarcocystosis among returning travelers - Tioman Island, Malaysia, 2011.MMWR Morb Mortal Wkly Rep. 2012;61(2):37-8.

2. Esposito DH, Freedman DO, Neumayr A, Parola P. Ongoing outbreak of an acute muscular Sarcocystis-like illness among travellers returning from Tioman Island, Malaysia, 2011-2012. Euro Surveill. 2012;17(45): pii=20310.

3. Tappe D, Ernestus K, Rauthe S, Schoen C, Frosch M, Müller A, Stich A. Initial patient cluster and first positive biopsy findings in an outbreak of acute muscular Sarcocystis-like infection in travelers returning from Tioman island, Peninsular Malaysia, in 2011. J Clin Microbiol. 2013;51(2):725-6. http://dx.doi. org/10.1128/JCM.03063-12

4. Slesak G, Tappe D, Keller C, Cramer J, Güthoff W, Zanger $\mathrm{P}$, et al. [Muscular sarcocystosis after travel to Malaysia: a case series from Germany]. Dtsch Med Wochenschr. 2014;139(19):990-5. German. http://dx.doi. org/10.1055/s-0034-1370004

5. Fayer R. Sarcocystis spp. in human infections. Clin Microbiol Rev. 2004;17(4):894-902. http://dx.doi.org/10.1128/ CMR.17.4.894-902.2004

6. Abubakar S, Teoh BT, Sam SS, Chang LY, Johari J, Hooi PS, et al. Outbreak of human infection with Sarcocystis nesbitti, Malaysia, 2012. Emerg Infect Dis. 2013;19(12):1989-91. http:// dx.doi.org/10.3201/eid1912.120530

7. Lau YL, Chang PY, Tan CT, Fong MY, Mahmud R, Wong KT. Sarcocystis nesbitti infection in human skeletal muscle: possible transmission from snakes. Am J Trop Med Hyg. 2014;90(2):361-4. http://dx.doi.org/10.4269/ajtmh.12-0678

8. Kan SP, Pathmanathan R. Review of sarcocystosis in Malaysia. Southeast Asian J Trop Med Public Health. 1991;22 Suppl:129-34.

9. Wong KT, Pathmanathan R. High prevalence of human skeletal muscle sarcocystosis in south-east Asia. Trans R Soc Trop Med Hyg. 1992;86(6):631-2. http://dx.doi. org/10.1016/0035-9203(92)90161-5

10. Arness MK, Brown JD, Dubey JP, Neafie RC, Granstrom DE. An outbreak of acute eosinophilic myositis attributed to human Sarcocystis parasitism. Am J Trop Med Hyg. 1999;61(4):548-53.

11. Husna Maizura AM, Khebir V, Chong CK, Azman Shah AM, Azri A, Lokman Hakim S. Surveillance for sarcocystosis in Tioman Island, Malaysia. Malaysian Journal of Public Health Medicine. 2012. 12(2).

12. Tian M, Chen $Y, W u L$, Rosenthal BM, Liu X, He Y, et al. Phylogenetic analysis of Sarcocystis nesbitti (Coccidia: Sarcocystidae) suggests a snake as its probable definitive host. Vet Parasitol. 2012;183(3-4):373-6. http://dx.doi. org/10.1016/j.vetpar.2011.07.034

13. Tappe D, Abdullah S, Heo CC, Kannan Kutty M, Latif B. Human and animal invasive muscular sarcocystosis in Malaysia--recent cases, review and hypotheses. Trop Biomed. 2013;30(3):355-66. 